\title{
El Perú y el Foro de Cooperación Económica Asia-Pacífico*
}

\author{
Julio Chan Sánchez
}

\section{RESUMEN}

Se presenta una breve explicación de la organización, estructura y funcionamiento del Foro de Cooperación Económica Asia-Pacífico (APEC) y de su importancia económica y comercial. Se analizan las relaciones comerciales y financieras del Perú con APEC y su progreso hacia la consecución de la liberalización y facilitación del comercio y la inversión (Metas de Bogor). Se informa de las más recientes actividades relacionadas al Área de Libre Comercio del Asia-Pacífico (FTAAP) para finalmente presentar el tema general y las prioridades peruanas, así como de las prioridades relativas al comercio exterior para 2016, año en que el Perú preside el Foro.

Palabras clave: APEC, relaciones Peru-APEC, liberalización y facilitación del comercio y la inversión, Metas de Bogor, Área de Libre Comercio del Asia Pacífico, FTAAP, prioridades APEC 2016.

\section{Peru and the Asia-Pacific Economic Cooperation Forum}

\section{Abstract}

A brief presentation of the organization, structure and functioning of the Asia-Pacific Economic Cooperation Forum (APEC) is followed by data reaffirming its economic importance. An analysis of trade and investment relations between Peru and APEC is presented as well as of Peru's progress towards trade and investment liberalization and facilitation (Bogor Goals). Most recent activities related to the Free Trade Area of the Asia-Pacific (FTAAP) are reported, and also Peru's general theme and priorities, as well as trade priorities for 2016, year in which Peru presides the Forum.

Key words: APEC, Peru-APEC relations, trade and investment liberalization and facilitation, Bogor Goals, Free Trade Area of the Asia-Pacific, FTAAP, APEC 2016 priorities.

\footnotetext{
* Me es muy grato expresar mi más profundo agradecimiento por el muy importante apoyo que el seńor Jorge Luis Oscátegui Pérez me ha brindado en la preparación del presente trabajo. Sin su valiosa colaboración los resultados serían otros. El autor, sin embargo, es el único responsable del presente documento.

** Coordinador general del Foro de Cooperación Económica Asia-Pacífico, del Ministerio de Comercio Exterior y Turismo (Mincetur), Lima, Perú. PhD. en Ciencia Política, Economista. Correo electrónico: jchan@mincetur.gob.pe
} 


\section{APEC: una revisión panorámica}

APEC (por las siglas en inglés de Asia-Pacific Economic Cooperation) identifica al Foro de Cooperación Económica Asia-Pacífico. El Foro agrupa a las siguientes 21 Economías': Australia, Brunéi Darussalam, Canadá, Chile, China Taipei, Estados Unidos de América, Filipinas, Hong Kong-China, Indonesia, Japón, Malasia, México, Nueva Zelanda, Papúa Nueva Guinea, Perú, República de Corea, República Popular China, Rusia, Singapur, Tailandia y Vietnam.

Cuadro 1. Economías miembro de APEC y fecha de ingreso al Foro

\begin{tabular}{ll}
\hline Economía miembro & Fecha de ingreso al Foro \\
\hline Australia & 6-7 de noviembre de 1989 \\
Brunéi Darussalam & 6-7 de noviembre de 1989 \\
Canadá & 6-7 de noviembre de 1989 \\
Estados Unidos & 6-7 de noviembre de 1989 \\
Filipinas & 6-7 de noviembre de 1989 \\
Indonesia & 6-7 de noviembre de 1989 \\
Japón & 6-7 de noviembre de 1989 \\
Malasia & 6-7 de noviembre de 1989 \\
Nueva Zelanda & 6-7 de noviembre de 1989 \\
República de Corea & 6-7 de noviembre de 1989 \\
Singapur & 6-7 de noviembre de 1989 \\
Tailandia & 6-7 de noviembre de 1989 \\
China Taipéi & $12-14$ de noviembre de 1989 \\
Hong Kong-China & $12-14$ de noviembre de 1989 \\
República Popular China & $12-14$ de noviembre de 1989 \\
México & $17-19$ de noviembre de 1989 \\
Papúa Nueva Guinea & $17-19$ de noviembre de 1989 \\
Chile & $11-12$ de noviembre de 1989 \\
Perú & $14-15$ de noviembre de 1989 \\
Rusia & $17-19$ de noviembre de 1989 \\
Vietnam & $17-19$ de noviembre de 1989 \\
\hline Fuent APEC Secretaiat Elaborien &
\end{tabular}

Fuente: APEC Secretariat. Elaboración: Mincetur.

Se denomina así a los miembros de APEC ya que no todos son Estados (APEC, 2016a). 
Constituido en 1989, es un Foro de consulta multilateral concebido para promover la cooperación económica, el crecimiento económico y la expansión del comercio entre sus miembros. Es único, ya que busca la integración regional a través de compromisos no vinculantes, permitiendo que cada Economía avance al ritmo de sus propias características, sensibilidades y particularidades. Además por la diversidad social, económica y regulatoria de la región y las diferencias en los ajustes de política doméstica en cada Economía, la naturaleza no vinculante de APEC facilita el logro de consensos para llevar a cabo acciones de carácter voluntario. Estas características diferencian a APEC de los acuerdos de libre comercio y de otro tipo de acuerdos y convenios (por ejemplo: OMC, ALADI, Acuerdo de Promoción Comercial Perú-EE UU.) que funcionan como compromisos contractuales y por ello de cumplimiento obligatorio.

El Foro tiene como objetivo la formación de la Comunidad del Asia-Pacífico por vía de la liberalización y facilitación del comercio y de la inversión para lo cual establecieron plazos: 2010 para los miembros industrializados y 2020 para las economías en desarrollo. Para ello, el hito trascendente es la Declaración de Bogor suscrita por los Líderes de las Economías de APEC, en su reunión de 1994, en la ciudad indonesia de ese nombre, que fijó la ruta de navegación, hoy vigente, y que se conocen como las «Metas de Bogor».

Para alcanzar las Metas de Bogor, las diversas y numerosas instancias del Foro van construyendo gradualmente, a través de acciones, una plataforma sostenida en los denominados «Tres pilares de APEC» (Mincetur, 2016):

- Liberalización del comercio y la inversión

La liberalización del comercio e inversión está enfocada en la apertura de los mercados y la reducción significativa de los obstáculos y restricciones al comercio y la inversión.

- Facilitación del comercio e inversión

La facilitación del comercio está enfocada en la reducción de los costos de transacción empresariales. También promueve el mejoramiento del acceso a la información comercial, maximizando los beneficios de la tecnología de la información. Esencialmente, la facilitación del comercio ayuda a los empresarios a llevar a cabo sus negocios más eficientemente en el Asia-Pacífico.

- Cooperación técnica y económica (ECOTECH)

La cooperación técnica y económica comprende actividades de cooperación para fortalecer las capacidades institucionales e individuales en diversos sectores de los 21 miembros. Su objetivo es que todos ellos puedan progresar en el proceso de liberalización y facilitación del comercio y las inversiones. 
Para medir el avance de las Economías hacia las Metas de Bogor, se llevan a cabo evaluaciones basadas en los Planes de Acción Individual (Individual Action Plans - IAP), presentadas por cada Economía, y los Planes de Acción Colectivos (Collective Action Plans - CAP) que detallan las acciones conjuntas entre las Economías miembro de APEC para las áreas temáticas señaladas en la Agenda de Acción de Osaka²

Los Planes de Acción Individual (IAP) en la actualidad abarcan los siguientes quince temas (Chan Sánchez, 2015):

\section{Gráfico 1}
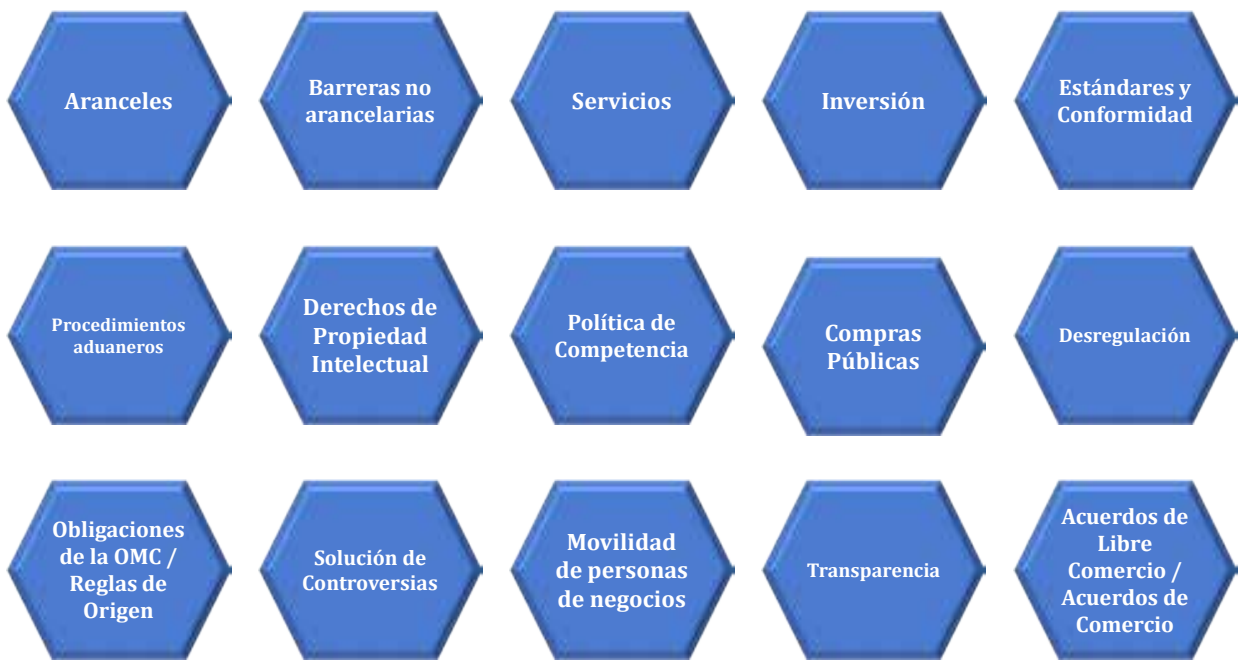

Fuente: Chan Sánchez (2015). Elaboración: Mincetur.

Los informes de la Unidad de Apoyo de Políticas de APEC (Policy Support Unit-PSU), de noviembre de 2010, agosto de 2012 y octubre de 2015, sobre los avances en las Metas de Bogor en materia de comercio e inversión, reportan los siguientes indicadores ${ }^{3}$ :

2 (OAA - Osaka Action Agenda) define las áreas de acción y los medios para alcanzar las Metas de Bogor

3 Policy Support Unit. (November, 2010). Progressing towards the APEC Bogor Goals Perspectives of the APEC. Recuperado de http://publications.apec.org/publication-detail.php?pub_id=1083. Policy Support Unit. (September, 2012). APEC's Bogor Goals Dashboard, August 2012. Recuperado de http://publications.apec.org/publicationdetail.php?pub_id=1309. Policy Support Unit. (October, 2015). APEC's Bogor Goals Dashboard, October 2015. Recuperado de http://publications.apec.org/publication-detail.php?pub_id=1665. 


\section{Cuadro 2}

\begin{tabular}{|c|c|c|c|c|c|c|c|c|}
\hline \multicolumn{2}{|c|}{ APEC } & 2008 & 2009 & 2010 & 2011 & 2012 & 2013 & 2014 \\
\hline \multicolumn{9}{|c|}{ Good Trade } \\
\hline 1 & $\begin{array}{l}\text { MFN Tariff } \\
\text { (HS 6-dgit level simple average) }\end{array}$ & 6.6 & 6.2 & 5.8 & 5.7 & 5.7 & 5.8 & \\
\hline 2 & $\begin{array}{l}\text { MFN Tariff - Agriculture } \\
\text { (HS 6-dgit level simple average) }\end{array}$ & 13.1 & 12.1 & 11.8 & 12.2 & 12.0 & 12.2 & \\
\hline 3 & $\begin{array}{l}\text { MFN Tariff - Non Agriculture } \\
\text { (HS 6-dgit level simple average) }\end{array}$ & 5.7 & 5.3 & 4.9 & 4.7 & 4.7 & 4.7 & \\
\hline 4 & Zero - Tariff Products Lines (\%) & 42.4 & 43.1 & 45.5 & 45.3 & 45.4 & 45.5 & \\
\hline 5 & Zero - Tariff Imports Lines (\%) & 56.4 & 59.6 & 60.2 & 60.8 & 60.0 & & \\
\hline 6 & $\begin{array}{l}\text { Percentage of Products Lines with } \\
\text { MFN Tariff Rates }>=10 \%\end{array}$ & 16.3 & 15.6 & 14.5 & 14.1 & 14.2 & 14.3 & \\
\hline 7 & Non-Ad Valorem Products Lines (\%) & 2.2 & 1.9 & 1.9 & 2.0 & 2.0 & 1.9 & \\
\hline 8 & Non-Ad Valorem Imports (\%) & 2.3 & 2.5 & 2.3 & 2.4 & 1.4 & & \\
\hline 9 & $\begin{array}{l}\text { Logistic Performance Index - } \\
\text { Overall Index (1=low, 5=high) }\end{array}$ & 3.35 & 3.38 & & 3.39 & & 3.42 & \\
\hline 10 & Lead Time to Exports (days) & 14.8 & 14.6 & 14.0 & 13.6 & 13.2 & 13.1 & 13.1 \\
\hline 11 & Lead Time to Imports (days) & 15.0 & 14.8 & 14.1 & 13.9 & 13.5 & 13.3 & 13.4 \\
\hline 12 & Cost to Export (USD per container) & 885.3 & 879.1 & 887.1 & 885.0 & 912.3 & 921.1 & 948.3 \\
\hline 13 & Cost to Import (USD per container) & 968.2 & 957.3 & 963.4 & 935.5 & 977.0 & 990.8 & $1,020.3$ \\
\hline 14 & Documents to Export (number) & 4.8 & 4.8 & 4.8 & 4.7 & 4.7 & 4.7 & 4.7 \\
\hline 15 & Documents to Import (number) & 6.0 & 5.8 & 5.7 & 5.7 & 5.7 & 5.6 & 5.6 \\
\hline \multicolumn{9}{|c|}{ Services } \\
\hline 16 & Services Sectors with GATS Commitments & 77 & 77 & 77 & 77 & 79 & 79 & 79 \\
\hline 17 & $\begin{array}{l}\text { «Best» RTA/FTA Services } \\
\text { Commitments Achieved } \\
(0=\text { no commitments, } 100=\text { full } \\
\text { commitments in all sectors })\end{array}$ & 51.03 & 56.93 & 56.95 & 56.95 & 57.30 & & \\
\hline 18 & $\begin{array}{l}\text { Number of RTA/FTAs with Sectorial } \\
\text { Sevices Commitments - Number of RTA/ } \\
\text { FTAs }\end{array}$ & $56-86$ & $67-98$ & 74-104 & $82-116$ & $89-126$ & $99-137$ & $105-143$ \\
\hline \multicolumn{9}{|c|}{ Investment } \\
\hline 19 & $\begin{array}{l}\text { Prevalence of Foreign Ownership } \\
(1=\text { very rare, } 7=\text { highest })\end{array}$ & 5.3 & 5.2 & 5.1 & 5.0 & 5.0 & 5.0 & 5.0 \\
\hline 20 & $\begin{array}{l}\text { Business Rules Impact on FDI } \\
(1=\text { very rare, } 7 \text { =highest })\end{array}$ & 5.4 & 5.2 & 5.0 & 5.0 & 5.0 & 4.9 & 4.9 \\
\hline
\end{tabular}

Fuente: Unidad de Apoyo de Políticas de APEC (Policy Support Unit-PSU). Elaboración: Mincetur. 
Para examinar el cuadro hay que tener en cuenta las siguientes referencias rápidas:

- Los promedios arancelarios MFN (nación más favorecida) están reportados a nivel de 6 dígitos del Sistema Armonizado de Mercancías (HS en inglés) y expresados en ad valorem, e incorpora las equivalencias de otras tarifas que no son ad valorem, y difieren de los informados por las Economías APEC. Los informes por país están expresados en 8 o 10 dígitos del HS según propio uso en cada caso.

- Los indicadores sobre la facilitación del comercio y la inversión se elaboran sobre la base de encuestas.

- Indicadores sobre el tiempo del trámite, los costos, y documentos de exportación e importación no toman en cuenta la ubicación o tamaño del país. Asume que la empresa conoce los procedimientos, que el transporte utilizado es el marítimo y advierte sobre las siguientes limitaciones,

1. Las encuestas se realizan a empresas con un mínimo de 60 empleados, que estén ubicadas en la ciudad de mayor concentración de negocios del país, pertenecen al sector privado, son $100 \%$ de propiedad nacional, exportan más del $10 \%$ de sus ventas y no estén instaladas en zonas francas, parques industriales, o espacios de privilegio para la exportación o importación.

2. Las encuestas recogen datos sobre un conjunto específico de temas, para un escenario estándar, por lo que puede no ser representativo del conjunto de negocios del país.

3. Las encuestas toman información de la ciudad de mayor concentración económica de cada país, por lo que deja de lado otras regiones o ciudades de la misma Economía.

- Los indicadores de servicios recogen solamente las medidas bilaterales, regionales y multilaterales de liberalización de su comercio, no toma en cuenta las unilaterales.

- La información sobre los Acuerdos Regionales y de Libre Comercio (RTA/ FTAs en inglés) cuantifica la profundidad de los compromisos, en servicios, logrado entre las Economías miembro de APEC que tienen en vigencia dichos Acuerdos en las prestaciones en modo 1 (comercio transfronterizo) y en el modo 3 (presencial).

Es conveniente tomar en cuenta que la Unidad de Apoyo de Políticas de APEC 4 , en 2010, ańo meta de los objetivos de Bogor para las Economías industrializadas, comenzó a elaborar este tipo de informe para ayudar a los miembros del Foro a evaluar los avances logrados. Para este primer ejercicio se contó con la participación

\footnotetext{
4 Policy Support Unit. (November, 2010). Progressing towards the APEC Bogor Goals Perspectives of the APEC. Recuperado de http://publications.apec.org/publication-detail.php?pub_id=1083.
} 
de las cinco economías industrializadas ${ }^{5}$ y la participación voluntaria de ocho economías en desarrollo ${ }^{6}$.

El informe está basado en información pública y se llegó a la conclusión que se había avanzado en la reducción de las barreras al comercio como en la promoción de la inversión desde 1994, año en que se establecieron las Metas de Bogor.

Con posterioridad se realizaron los siguientes informes:

Progressing towards the APEC Bogor Goals Perspectives of the APEC Policy Support Unit

APEC's Bogor Goals Dashboard, August 2012

APEC's Bogor Goals Progress Report, August 2012

APEC's Bogor Goals Dashboard, May 2013

APEC's Bogor Goals Dashboard 2014, August 2014

APEC's Bogor Goals Progress Report 2014, August 2014

APEC's Bogor Goals Dashboard 2015, October 2015

Los resultados, en general, muestran que el progreso es significativo en los diversos campos de la economía, el comercio, la inversión, y las de carácter social. Factor decisivo en los avances es la acción concertada de los países miembros. Las Economías de APEC, han superado al resto del mundo.

Más allá de los resultados positivos, logrados al 2010 y las conclusiones de los estudios mencionados, todavía se requieren esfuerzos adicionales debido a que el progreso ha sido desigual en los distintos sectores. Sin embargo, las evidencias muestran que la brecha de desarrollo se está reduciendo entre los miembros de APEC y que están enrumbadas al crecimiento sostenible, el desarrollo equitativo y el fortalecimiento de la Comunidad del Asia-Pacífico.

\section{Estructura de APEC}

La estructura organizativa del Foro contiene dos niveles, el nivel político y el nivel técnico ${ }^{7}$ :

A nivel politico, la dirección emana de los 21 líderes de las Economías de APEC, mientras que las recomendaciones estratégicas son proporcionadas por los ministros del Foro.

\footnotetext{
Australia, Canadá, Estados Unidos, Japón y Nueva Zelanda.

Chile, China-Taipéi, Hong Kong-China, Malasia, México, Perú, República de Corea y Singapur.

7 APEC Secretariat. APEC Structure (February 2016). Recuperado de http://www.apec.org/About-Us/HowAPEC-Operates/Structure.aspx
} 


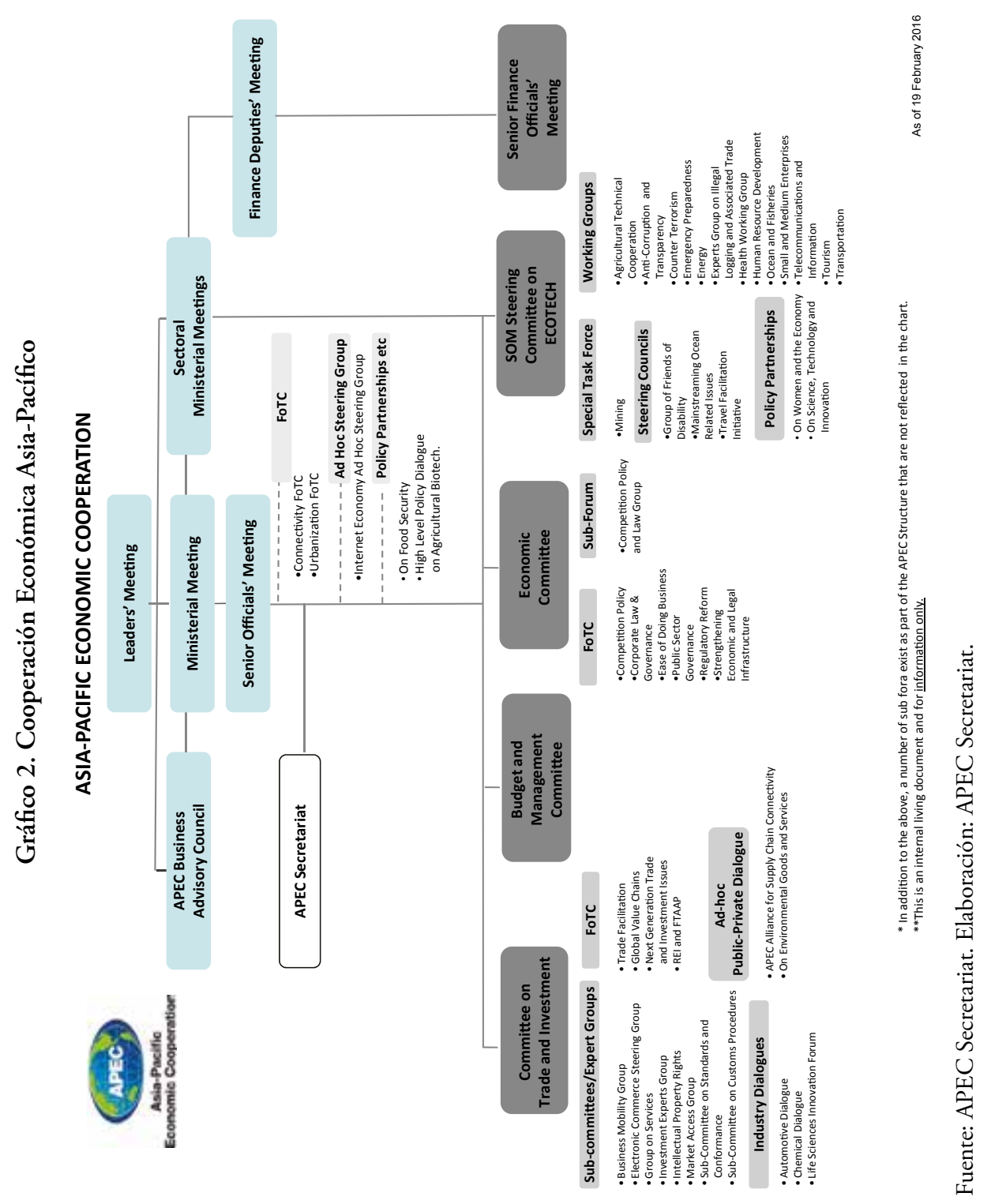


Las siguientes reuniones, que se llevan a cabo cada año, ayudan a dar forma a la dirección política de APEC.

\section{a) Reunión de Líderes de las Economías (AELM: APEC Economic Leaders' Meeting)}

Es la última reunión del año y la más importante ${ }^{8}$, se celebra una vez al año en la Economía anfitriona de APEC, en ella se toma conocimiento de los temas avanzados y se adoptan decisiones. Al culminar la reunión se dan a conocer los acuerdos e instrucciones, a través de la Declaración de Líderes, la que fija la agenda futura de la APEC.

\section{b) Reunión de Ministros (AMM: APEC Ministerial Meeting)}

Reunión previa a la Reunión de Líderes?. Reunión conjunta de los ministros responsables de Comercio Exterior y ministros de Relaciones Exteriores consensuan los temas a ponerse a consideración de los líderes. Al culminar la reunión se da a conocer una declaración donde se detallan los resultados más importantes y los acuerdos a este nivel.

\section{c) Reuniones Ministeriales Sectoriales (Sectoral Ministerial Meetings)}

Estas reuniones son convocadas por la Economía interesada por lo que su frecuencia no es regular en la mayoría de los casos. Se cubren áreas como educación, energía, medio ambiente y desarrollo sostenible, finanzas, desarrollo de recursos humanos, cooperación científica y tecnológica regional, pequeñas y medianas empresas, telecomunicaciones e industria de la información, turismo, comercio, transporte y asuntos de la mujer. Es costumbre que la Economía anfitriona del año convoque a reuniones de ministros de Comercio Exterior, de Pymes y de Finanzas. Algunas reuniones ministeriales son bienales, como es el caso de la de los ministros de Turismo.

En estas reuniones se discuten temas específicos de la agenda APEC de relevancia para el sector. Los ministros a través de declaraciones, dan a conocer los avances logrados y decisiones adoptadas. Estas sirven de insumos para los altos funcionarios y los comités y grupos de trabajo relevantes. Los principales logros y acuerdos ministeriales son recogidos en la declaración de la reunión anual de ministros de Comercio Exterior y de Relaciones Exteriores; y si fuese el caso, en la declaración de los líderes.

\footnotetext{
8 La primera reunión de Líderes se realizó, a convocatoria del presidente de EE.UU., Bill Clinton, en noviembre de 1993, en Blake Island, Seattle, EE.UU.

9 Entre 1989 y 1992, este fue el órgano de toma de decisiones más importante del Foro.
} 


\section{d) Reunión de Altos Funcionarios (SOM: Senior Officials' Meeting)}

Las reuniones formales tienen actualmente una frecuencia de cuatro veces por año. Los altos funcionarios guían las actividades de los comités, grupos de trabajo y grupos de acción. Informan sobre los avances y resultados, a la vez que presentan recomendaciones a ministros y líderes. Así mismo, velan por cumplir lo acordado por los ministros y líderes en declaraciones anteriores.

A nivel técnico se realizan reuniones de cuatro comités en los márgenes de las reuniones de altos funcionarios. Estos informan de los avances y solicitan instrucciones a los altos funcionarios. Las labores de los comités sirven de sustento técnico para futuras declaraciones ministeriales y de líderes. Los comités son:

\section{Comité de Comercio e Inversión (CTI: Committee on Trade and Investment)}

Coordina el trabajo de APEC sobre la liberalización y facilitación del comercio y la inversión, también trabaja para reducir los obstáculos a la actividad empresarial a través de sus Subcomités y Grupos de Expertos.

\section{Comité de Presupuesto y Administración (BMC: Budget and Management Committee)}

Asesora al SOM en asuntos presupuestales, administrativos y de gestión. También supervisa y evalúa los aspectos de gestión de proyectos de las operaciones de los Comités y Grupos de Trabajo y hace recomendaciones al SOM para mejorar la eficiencia y la eficacia.

\section{Comité Económico (EC: Economic Committee)}

Tiene el mandato de promover la reforma estructural dentro de APEC mediante la realización de análisis de políticas y el trabajo orientado a la acción en estrecha coordinación con otros grupos relevantes de APEC.

\section{Comité de Altos Funcionarios sobre Cooperación Económica y Técnica} (SCE: SOM Committee on Economic and Technical Cooperation-ECOTECH $)^{10}$

Está a cargo de la coordinación y gestión de la agenda de cooperación económica y técnica, así como la identificación de iniciativas para la acción cooperativa por las Economías miembro.

\footnotetext{
10 Los comités (excepto el de Presupuesto y Administración) a su vez, tienen el apoyo especializado de subcomités, grupos de trabajo, grupos / equipos ad hoc temporales. Sobre las actividades de algunos de estos subforos, véase González Vigil y Gala (2008).
} 
La participación y apoyo empresarial y académico se lleva a cabo a través del Consejo Consultivo Empresarial de APEC (ABAC) y del Consorcio de Centros de Estudios de APEC (ASC).

\section{a. ConsejoConsultivoEmpresarialdeAPEC(ABAC-APECBusinessAdvisoryCouncil)}

El Consejo Consultivo Empresarial, establecido en 1995, se reúne cuatro veces al año y sus representantes asisten como observadores a las reuniones ministeriales. $\mathrm{Su}$ objetivo es hacer seguimiento de las acciones del Foro. Ofrece sus puntos de vista y sugerencias a los líderes sobre la implementación de la agenda APEC. Los representantes son tres empresarios designados por el líder de cada Economía. Se suele designar también, hasta tres representantes alternos.

El ABAC es presidido por un miembro de la Economía que preside el APEC, este desempeña sus funciones junto con dos vicepresidentes. Estos últimos deben de pertenecer a la economía que presidió el APEC un año antes y a aquella que lo realizará el ańo siguiente (Sociedad de Comercio Exterior del Perú, 2016).

\section{b. Centros de Estudios APEC (ASC-APEC Studies Center)}

Los Centros de Estudios APEC forman parte de la iniciativa de los líderes de APEC para fomentar la cooperación académica regional entre las universidades y centros de investigación que permitan enfrentar los retos económicos regionales.

Los Centros de Estudios APEC tienen como objetivo investigar, difundir información y facilitar el debate sobre los temas y procesos en torno a la visión y los objetivos de APEC, juntos forman el Consorcio de Centros de Estudios APEC.

El proceso APEC también se apoya en las labores de una Secretaría, con sede en Singapur. Es la encargada de coordinar el apoyo técnico y de consultoría a las Economías. Está dirigida por un director ejecutivo ${ }^{11}$.

\section{Dimensión económica de APEC $^{12}$}

\subsection{APEC en la economía global-2014}

Agrupa al 39\% de la población, contribuye con un 58\% al PBI mundial y sus importaciones y exportaciones globales suman el $49 \%$ del comercio mundial.

\footnotetext{
11 Hasta 2009, el cargo fue ocupado por un funcionario destacado por la Economía anfitriona. Este funcionario asumía, el ańo anterior, el puesto de director ejecutivo asociado (Deputy Executive Director). Desde 2010, los altos funcionarios seleccionan al director ejecutivo a través de una convocatoria pública.

12 APEC Policy Support Unit. APEC in Charts 2015. (pp. 3, 4, 5, 12, 23, 26). Recuperado de http://publications. apec.org/publication-detail.php?pub_id=1675
} 


\section{Gráfico 3}
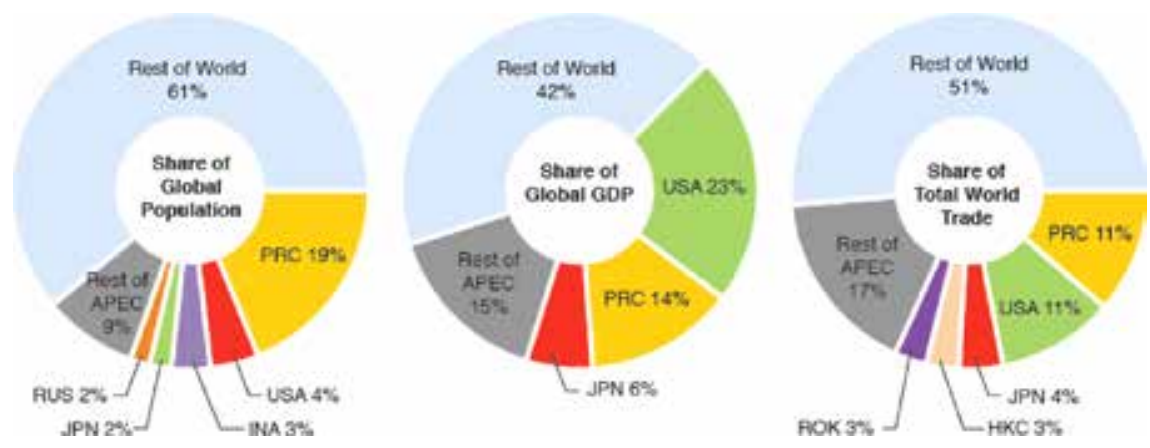

Fuente: APEC Policy Support. Elaboración: APEC Policy Support

En el período 2009-2014 el producto bruto interno de APEC ha crecido a un ritmo promedio anual de $6 \%$, versus el $5 \%$ registrado por el mundo, y el comercio a una tasa promedio anual de $10 \%$, frente al $9 \%$ del mundo.

\subsection{PBI per cápita (en dólares corrientes) - 2014}

El PBI per cápita, alcanzado por el bloque el año 2014 fue de US\$15 601 el cual se encuentra por encima del PBI per cápita de US\$ 14262 registrado en el mundo (Vásquez Vela, 2015).

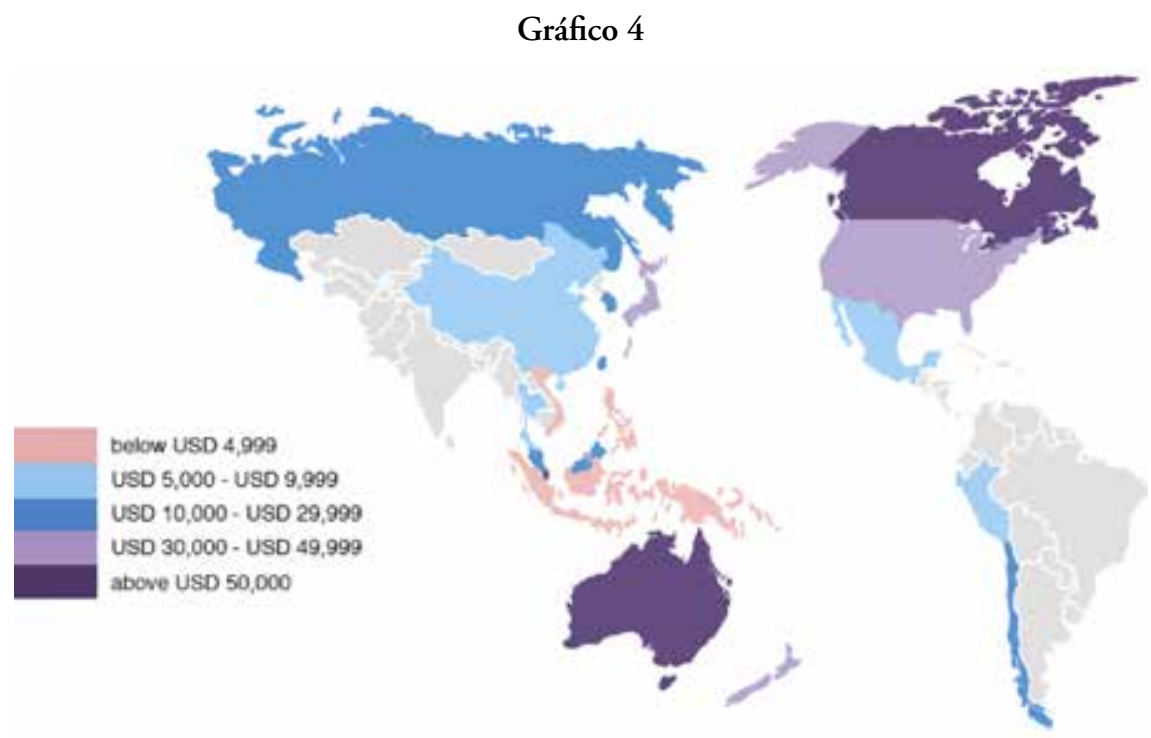

Fuente: APEC Policy Support. Elaboración: APEC Policy Support. 


\subsection{Crecimiento real del PBI (en porcentaje) - 2014}

La región de APEC registró un crecimiento real del PIB del 3,2\% en 2014, superior al crecimiento del PBI mundial del 2,5\% alcanzado en dicho ańo. Influyeron en estos resultados las incertidumbres en los precios del petróleo, el moderado crecimiento en China, y la regulación monetaria en Estados Unidos combinado con factores internos de los países miembros como un menor gasto de los hogares.

\section{Gráfico 5}
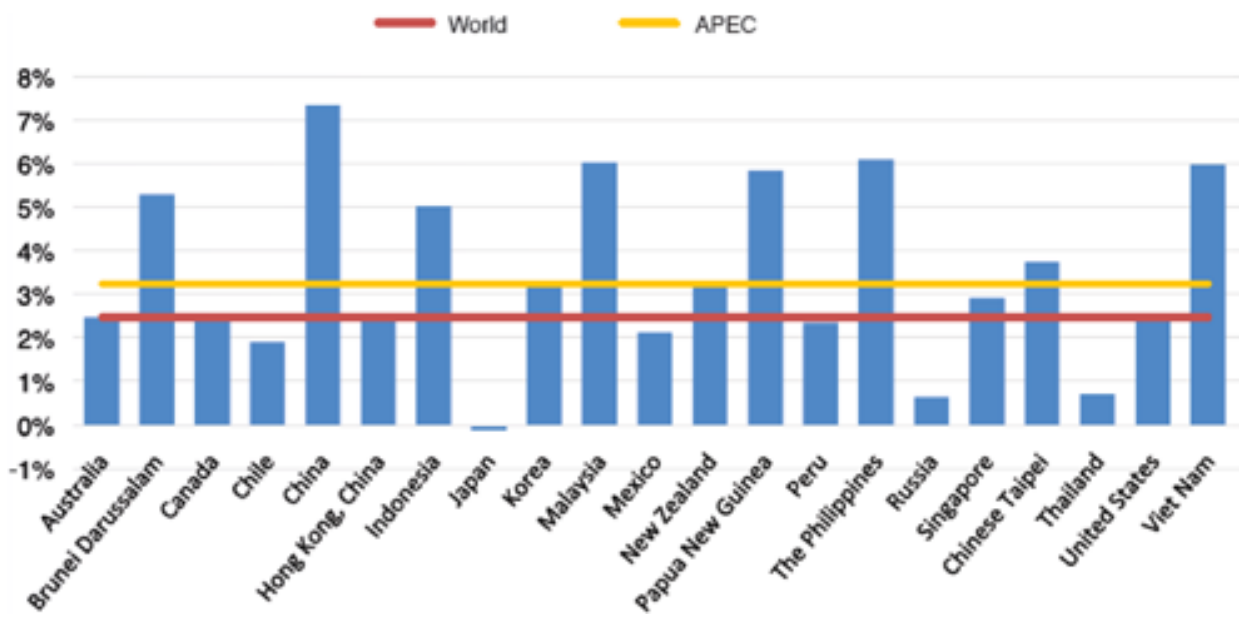

Fuente: APEC Policy Support. Elaboración: APEC Policy Support.

\subsection{Crecimiento del comercio en APEC (en porcentaje interanual) 2000-2014}

El crecimiento del comercio en la región ha ido disminuyendo en los últimos años como reflejo de los comportamientos desiguales de los países ante la crisis financiera global. El valor total de las exportaciones totales del APEC creció solo en 1,9\% el 2014 y las importaciones crecieron $0,3 \%$. 


\section{Gráfico 6}

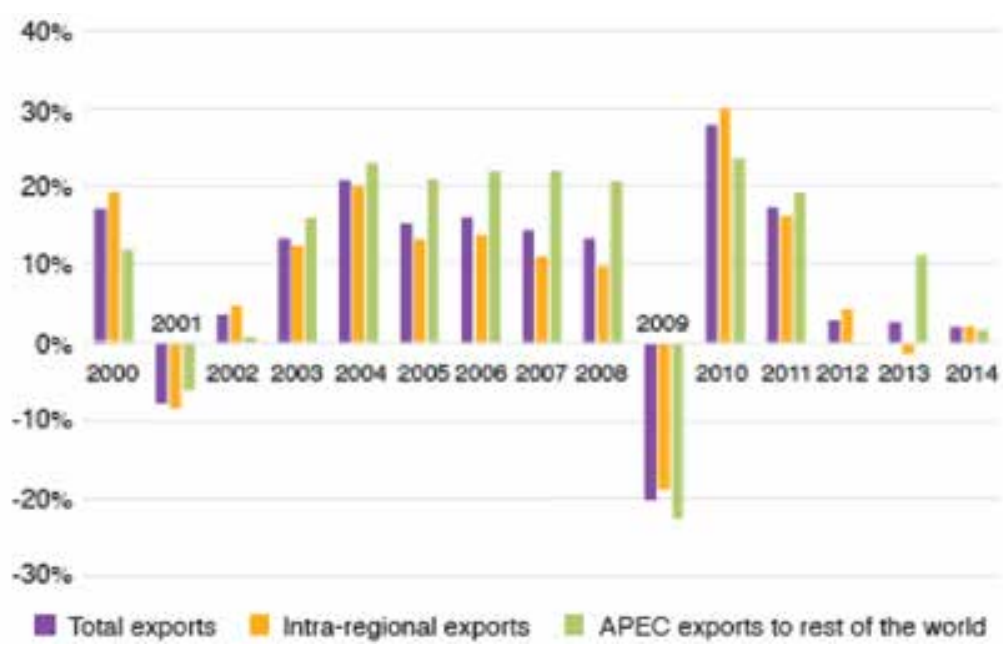

Fuente: APEC Policy Support. Elaboración: APEC Policy Support.

\section{Gráfico 7}

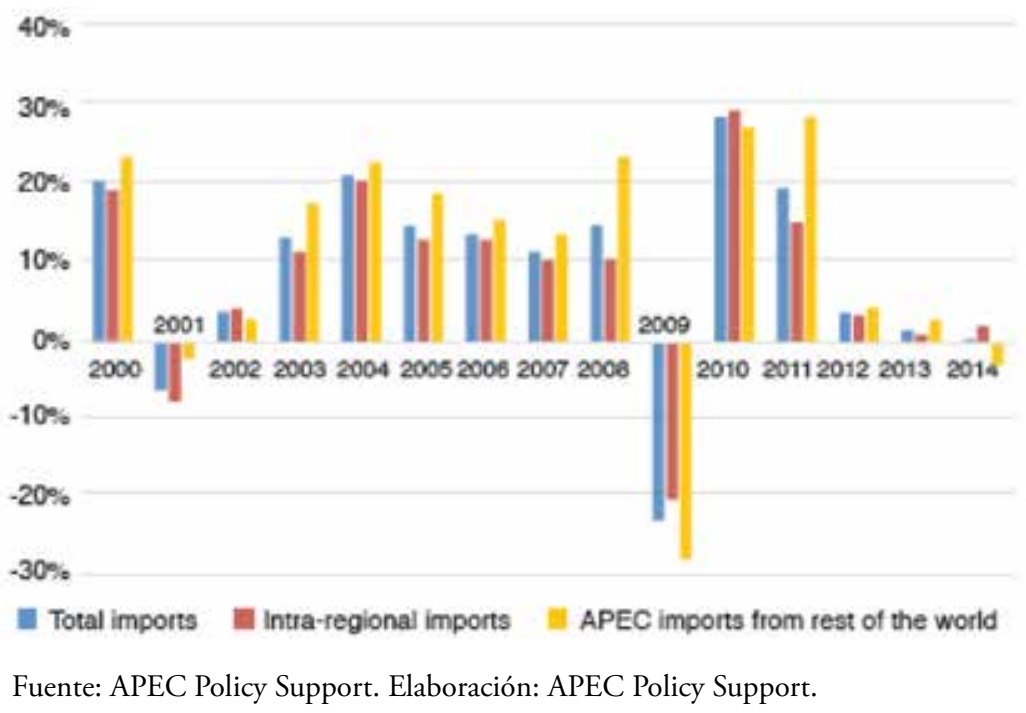

\subsection{Los cinco países mayores de APEC, en recepción y provisión de inversión extranjera directa (IED) (porcentaje de participación)}

El gráfico muestra, para el año 2014, que cinco países miembros absorbieron el 68\% de las IED y cinco proveyeron el 79\% de las inversiones directas en ese año. Nótese que cuatro se repiten en ambas posiciones. Singapur y Japón introducen las variantes. 


\section{Gráfico 8}
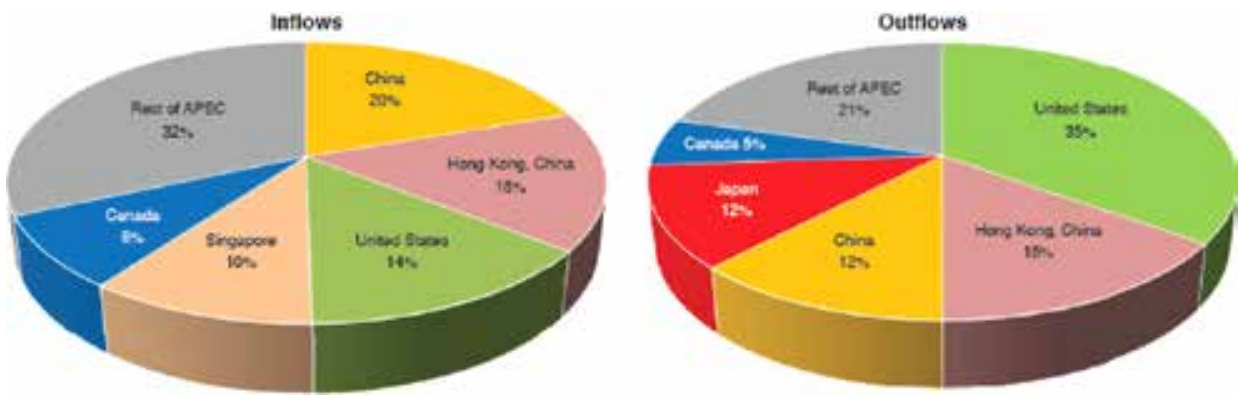

Fuente: APEC Policy Support. Elaboración: APEC Policy Support.

\section{6. Índice de desempeño logístico (puntuación total), 2014}

Las Economías de APEC obtuvieron una puntuación promedio de 3,4 en el índice de desempeńo logístico (LPI) en 2014, sobre un máximo de 5 puntos. El LPI pondera el desempeño de las Economías en sus aduanas, la infraestructura, los envíos internacionales, la calidad de la logística, la competencia, el seguimiento, la localización y la oportunidad de la gestión.

\section{Gráfico 9}

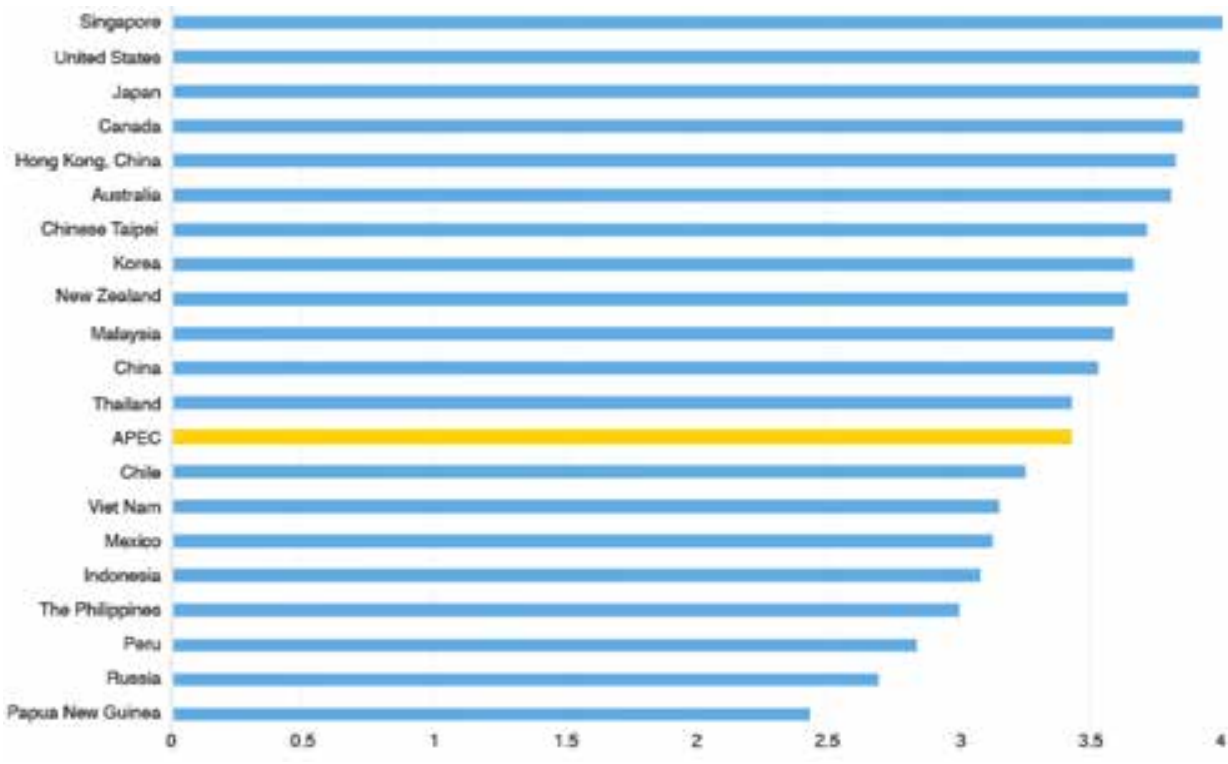

Fuente: APEC Policy Support. Elaboración: APEC Policy Support. 


\section{La integración del Perú en el Foro}

El Perú, en el proceso de internacionalización de su economía en la década de 1990, decide incorporarse a APEC que le ofrece una plataforma de concertación intergubernamental para el intercambio de buenas prácticas de políticas económicas y de comercio dentro de una de las regiones más dinámicas del mundo. Fue, formalmente aceptado, como miembro junto con Rusia y Vietnam en 1998 durante la Cumbre de Líderes de Kuala Lumpur, Malasia.

En el camino de su integración internacional, el Perú ha suscrito a diversos acuerdos multilaterales — regionales, subregionales_y bilaterales (Mincetur, 2016):

Gráfico 10. Acuerdos comerciales vigentes

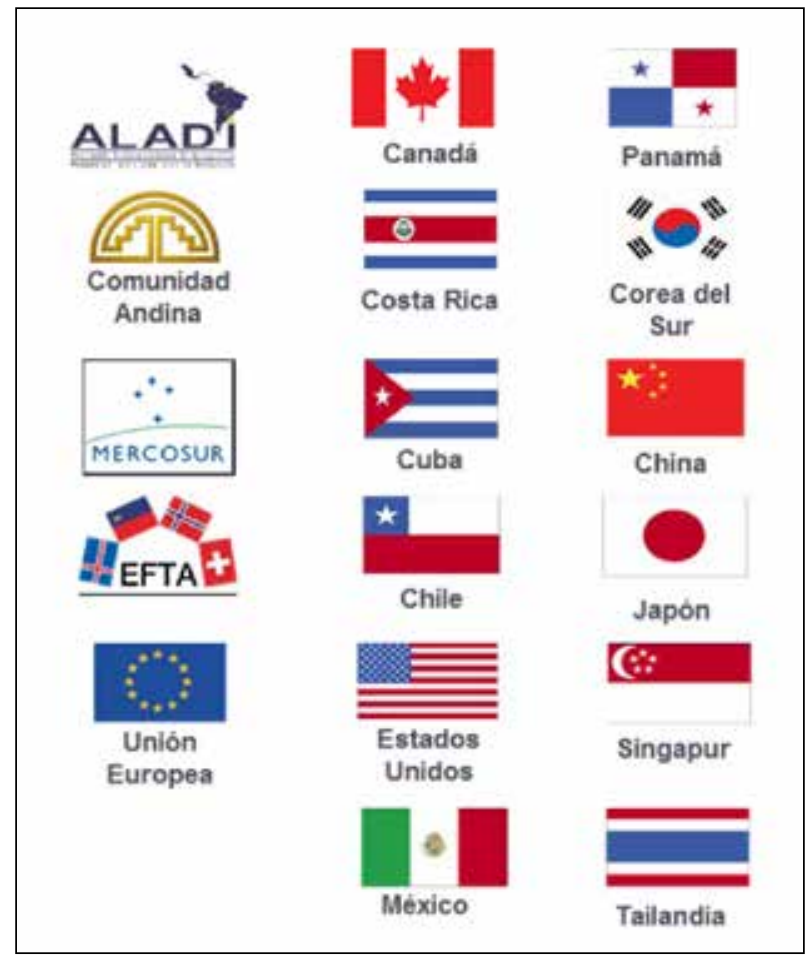

Fuente: Mincetur - Acuerdos comerciales. Elaboración: Mincetur. 
Gráfico 11. Acuerdos comerciales firmados

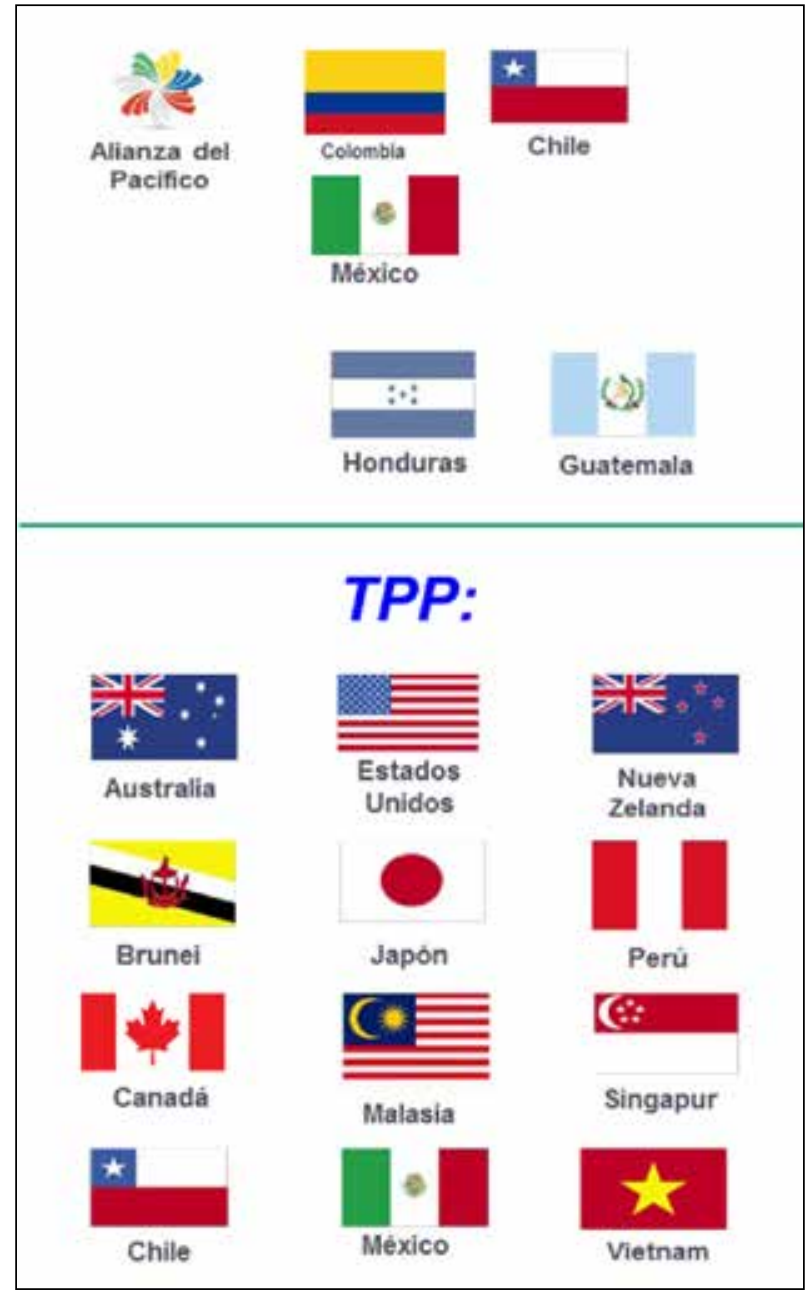

Fuente: Mincetur - Acuerdos comerciales. Elaboración: Mincetur.

\subsection{El comercio con APEC}

Los beneficios de la participación del Perú en APEC, transcurridos diecisiete años desde su ingreso, se pueden mostrar en los resultados siguientes: 
Gráfico 12. Exportaciones peruanas a APEC

(US\$ millones)

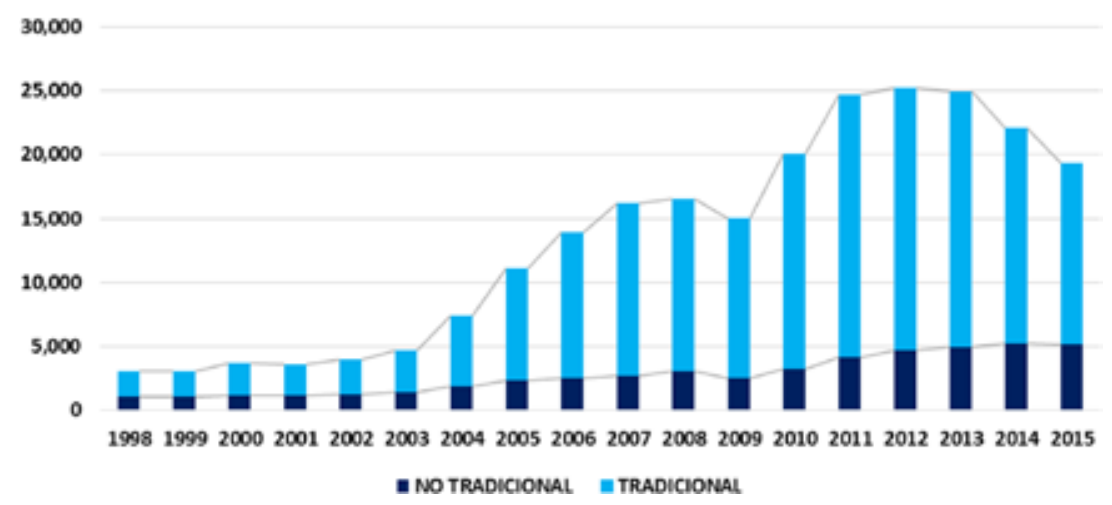

Fuente: Sunat. Elaboración: Mincetur.

En 2015, las exportaciones peruanas a APEC representaron el 58\% de sus ventas totales al mundo, los productos tradicionales representaron el $73 \%$ del total de exportaciones al APEC y el 67\% de las exportaciones al mundo. Las exportaciones de productos no tradicionales representaron el $27 \%$ del total de exportaciones a APEC y el 33\% de las exportaciones al mundo.

Desde su ingreso las exportaciones del Perú a APEC han crecido a un promedio anual de $11 \%$, las exportaciones tradicionales en $12 \%$ y las no tradicionales en $9 \%$, respectivamente. En el mismo período, las exportaciones peruanas al resto del mundo tuvieron una tasa de crecimiento anual de 10\%, las exportaciones tradicionales $9 \%$ y las exportaciones no tradicionales $10 \%$.

\section{Gráfico 13. Exportaciones peruanas por mercados}

(US\$ millones)

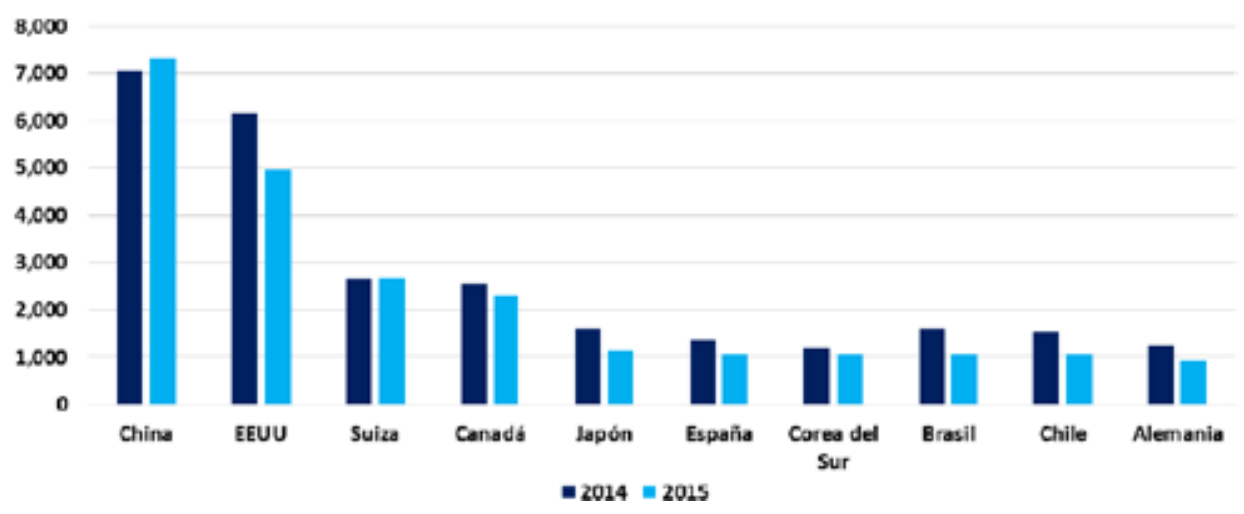

Fuente: Sunat. Elaboración: Mincetur. 
Los diez principales mercados del Perú a nivel mundial concentran el $71 \%$ de las exportaciones totales, seis de ellos son Economías miembro de APEC: China, Estados Unidos, Canadá, Japón, Corea del Sur y Chile que representaron el 54\%. En general, las exportaciones peruanas a estos diez mercados disminuyeron en 2015 respecto del año anterior, salvo las exportaciones a China y Suiza, respectivamente, que experimentaron un ligero incremento.

Gráfico 14. Importaciones peruanas desde APEC

(US\$ millones)

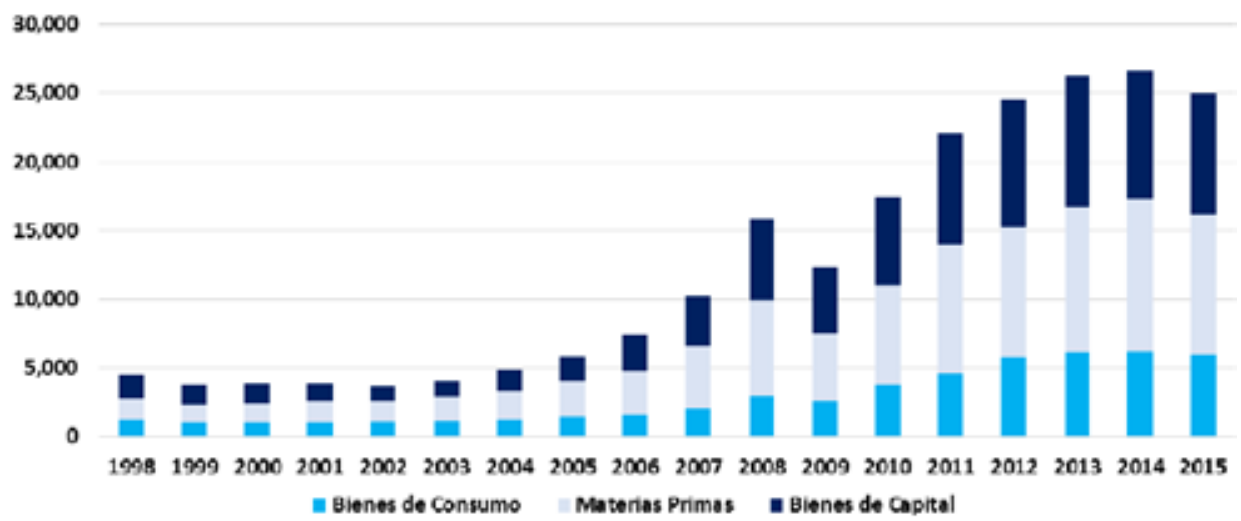

Fuente: Sunat. Elaboración: Mincetur.

Las importaciones peruanas desde APEC, en 2015, representaron el 66\% de sus compras totales del mundo. Las materias primas representaron el $41 \%$ del total de importaciones desde APEC. Mientras que los bienes de consumo y de capital representaron, respectivamente, el $24 \%$ y $35 \%$ del total de importaciones de dicho año. La tasa de crecimiento promedio anual de las importaciones peruanas, desde su ingreso al Foro en 1998, fue de $10 \%$, en tanto que la tasa de crecimiento registrada para el resto del mundo fue de $7 \%$.

Los diez principales proveedores del Perú a nivel mundial concentran el $71 \%$ de las importaciones totales de 2105, seis de ellos son Economías miembro de APEC: China, Estados Unidos, México, Corea del Sur Chile y Japón que representaron el $57 \%$. En general, las importaciones peruanas desde estos diez mercados disminuyeron en 2015 respecto del año anterior. 


\section{Gráfico 15. Importaciones peruanas por mercados}

(US\$ millones)

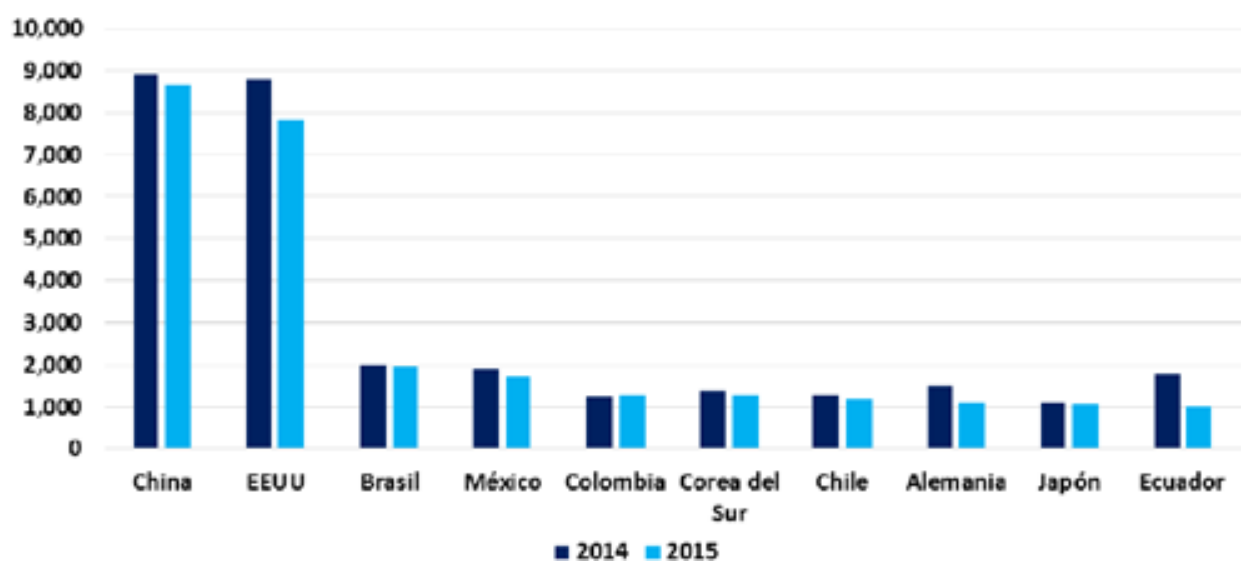

Fuente: Sunat. Elaboración: Mincetur.

\subsection{Inversión extranjera directa (IED) de los países de APEC en Perú ${ }^{13}$}

El 32,5\% del stock de la IED en Perú (1980 al 30 de Junio 2015), proviene de los países de APEC específicamente de 11 países, de los cuales Chile y Estados Unidos representan el $22,4 \%$.

Cuadro 3. Estructura del stock de IED de las Economías miembro de APEC por sectores 1980-2015 (enero-junio)

\begin{tabular}{|l|c|c|l|}
\hline Sector & US\$ millones & Part. $(\%)$ & País de origen \\
\hline Comercio & 305.8 & 3,9 & Chile y China \\
\hline Comunicaciones & 1148.9 & 14,7 & México y EE.UU. \\
\hline Energía & 819.5 & 10,5 & EE.UU. y Singapur \\
\hline Finanzas & 1832.2 & 23,4 & Canadá, Chile, EE.UU., México y Japón \\
\hline Industria & 1186.0 & 15,1 & Chile, EE.UU. y Corea del Sur \\
\hline Minería & 1885.0 & 24,1 & Canadá, Chile, EE.UU., México y Japón \\
\hline Pesca & 107.1 & 1,4 & Singapur \\
\hline Petróleo & 164.0 & 2,1 & EE.UU. \\
\hline Servicios & 168.2 & 2,1 & Chile y EE.UU. \\
\hline Otros & 219,5 & 2,8 & \\
\hline Total & $\mathbf{7 8 3 6 , 2}$ & $\mathbf{1 0 0}$ & \\
\hline
\end{tabular}

Fuente: Proinversión (actualizado al 30 de junio de 2015). Elaboración: Mincetur-VMCE-DGIECE. 13 Reporte de Comercio Bilateral Perú-Foro de Cooperación Económica Asia-Pacífico (APEC). (Ene-Nov. 2015).
Ministerio de Comercio Exterior, Dirección General de Investigación y Estudios sobre Comercio Exterior. 
Gráfico 16. Evolución del Flujo de IED de las Economías miembro de APEC en Perú 2005-2015 (enero-junio) (US\$ millones)

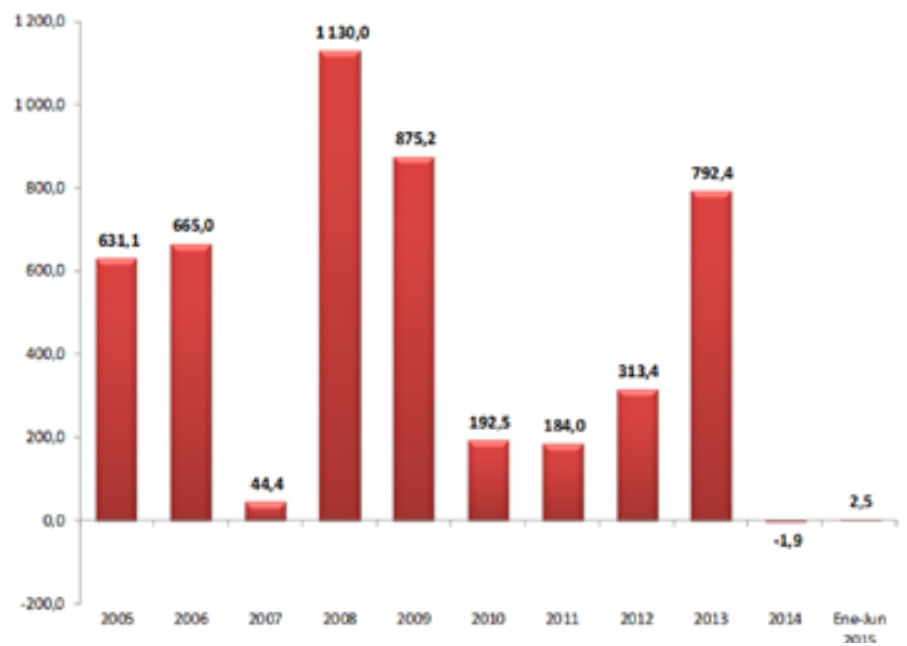

Fuente: Proinversión (actualizado al 30 de junio de 2015). Elaboración: Mincetur-VMCE-DGIECE.

El stock de la IED de los países de APEC en el Perú es muy variable, el pico fue en 2008 cuando se registraron US\$ 1130 millones de dólares. En el primer semestre de 2015 se registró una IED solo de US\$ 2,5 millones de dólares.

\subsection{El turismo}

Gráfico 17. Arribo de turistas al Perú por nacionalidad - 2014 14

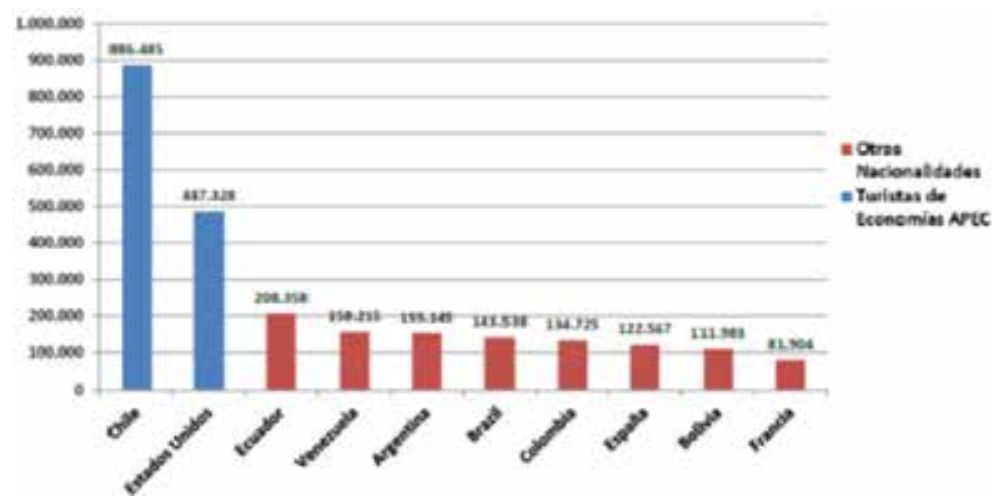

Fuente: Chan Sánchez - La Alianza del Pacífico y APEC: Agenda del Perú para el 2016.

\footnotetext{
14 Chan Sánchez, Julio (agosto de 2015). La Alianza del Pacifico y APEC. Agenda del Perú para el 2016. Presentación efectuada en Medellín, Colombia. Recuperado de http://www.kas.de/wf/doc/kas_16739-1442-1-30.pdf?150902212519
} 
Solo hay presencia de dos miembros APEC, Chile y Estados Unidos, entre las 10 principales nacionalidades de turistas que visitaron el Perú el año 2014 pero hay que tomar nota que ambos países conforman el 55\% del conjunto. Entre el 2010 y 2014, el flujo de turistas provenientes de las Economías APEC se incrementó en 40\%.

\subsection{Evaluación de avance a las Metas de Bogor $2015^{15}$}

Los informes de la Unidad de Apoyo de Políticas de APEC (Policy Support Unit-PSU), de noviembre de 2010, agosto de 2012 y octubre de 2015, sobre los avances en las Metas de Bogor en materia de comercio e inversión, reportan los siguientes indicadores:

\section{Cuadro 4}

\begin{tabular}{|c|c|c|c|c|c|c|c|c|}
\hline \multicolumn{2}{|c|}{ APEC } & 2008 & 2009 & 2010 & 2011 & 2012 & 2013 & 2014 \\
\hline \multicolumn{9}{|c|}{ Good Trade } \\
\hline 1 & $\begin{array}{l}\text { MFN Applied Tariff } \\
\text { (HS 6-dgit level simple average) }\end{array}$ & 6.1 & 5.5 & 5.4 & 3.7 & & 3.4 & \\
\hline 2 & $\begin{array}{l}\text { MFN Applied Tariff - Agriculture } \\
\text { (HS 6-dgit level simple average) }\end{array}$ & 10.0 & 6.2 & 6.3 & 4.1 & & 4.0 & \\
\hline 3 & $\begin{array}{l}\text { MFN Applied Tariff - Non Agriculture } \\
\text { (HS 6-dgit level simple average) }\end{array}$ & 5.5 & 5.4 & 5.2 & 3.6 & & 3.3 & \\
\hline 4 & Zero - Tariff Products Lines (\%) & 47.1 & 50.6 & 51.4 & 53.2 & & 54.0 & \\
\hline 5 & Zero - Tariff Imports Lines (\%) & 73.8 & 72.4 & 72.3 & 73.9 & 74.4 & & \\
\hline 6 & $\begin{array}{l}\text { Percentage of Products Lines with } \\
\text { MFN Tariff Rates }>=10 \%\end{array}$ & 16.4 & 12.9 & 12.4 & 12.4 & & 12.1 & \\
\hline 7 & Non-Ad Valorem Products Lines (\%) & 0.0 & 0.0 & 0.0 & 0.0 & & 0.0 & \\
\hline 8 & Non-Ad Valorem Imports (\%) & 0.0 & 0.0 & 0.0 & 0.0 & 0.0 & & \\
\hline 9 & $\begin{array}{l}\text { Logistic Performance Index - } \\
\text { Overall Index (1=low, 5=high) }\end{array}$ & 2.77 & 2.80 & & 2.94 & & 2.84 & \\
\hline 10 & Lead Time to Exports (days) & 22 & 21 & 12 & 12 & 12 & 12 & 12 \\
\hline 11 & Lead Time to Imports (days) & 25 & 24 & 17 & 17 & 17 & 17 & 17 \\
\hline 12 & Cost to Export (USD per container) & 860 & 860 & 860 & 860 & 890 & 890 & 890 \\
\hline 13 & Cost to Import (USD per container) & 895 & 895 & 880 & 880 & 880 & 1010 & 1010 \\
\hline 14 & Documents to Export (number) & 5 & 5 & 5 & 5 & 5 & 5 & 5 \\
\hline 15 & Documents to Import (number) & 7 & 7 & 7 & 7 & 7 & 7 & 7 \\
\hline
\end{tabular}

15 Policy Support Unit. (November, 2010). Progressing towards the APEC Bogor Goals Perspectives of the APEC. Recuperado de http://publications.apec.org/publication-detail.php?pub_id=1083. Policy Support Unit. (September, 2012). APEC's Bogor Goals Dashboard, August 2012. Recuperado de http://publications.apec.org/publicationdetail.php?pub_id=1309. Policy Support Unit. (October, 2015). APEC's Bogor Goals Dashboard, October 2015. Recuperado de http://publications.apec.org/publication-detail.php?pub_id=1665. 


\begin{tabular}{|c|c|c|c|c|c|c|c|c|}
\hline \multicolumn{9}{|c|}{ Services } \\
\hline 16 & Services Sectors with GATS Commitments & 49 & 49 & 49 & 49 & 49 & 49 & 49 \\
\hline 17 & $\begin{array}{l}\text { «Best» RTA/FTA Services } \\
\text { Commitments Achieved } \\
(0=\text { no commitments, } 100=\text { full } \\
\text { commitments in all sectors })\end{array}$ & 84.59 & 84.59 & 84.59 & 84.59 & & & \\
\hline 18 & $\begin{array}{l}\text { Number of RTA/FTAs with Sectorial } \\
\text { Sevices Commitments - Number of RTA/ } \\
\text { FTAs }\end{array}$ & $1-3$ & $5-7$ & $6-8$ & $7-11$ & $10-14$ & $12-17$ & $12-17$ \\
\hline \multicolumn{9}{|c|}{ Investment } \\
\hline 19 & $\begin{array}{l}\text { Prevalence of Foreign Ownership } \\
(1=\text { very rare, } 7=\text { highest })\end{array}$ & 5.9 & 5.8 & 5.6 & 5.4 & 5.3 & 5.2 & 5.0 \\
\hline 20 & $\begin{array}{l}\text { Business Rules Impact on FDI } \\
\text { (1=very rare, } 7=\text { highest })\end{array}$ & 5.6 & 5.6 & 5.4 & 5.4 & 5.3 & 5.1 & 4.7 \\
\hline
\end{tabular}

Fuente: Unidad de Apoyo de Políticas de APEC (Policy Support Unit-PSU).

\subsection{Evaluación de la participación del Perú en APEC}

Según un artículo del presidente del ABAC 2016 (APEC Business Advisory Council), o Consejo Consultivo Empresarial del Foro, el empresario peruano Juan Francisco Raffo, «los resultados han sido positivos en todos los frentes» ${ }^{16}$ :

- Se ha beneficiado de un mayor acceso a mercados, demostrado por el dinámico incremento del comercio con los países de la región, con un crecimiento promedio anual de 12\% registrado entre 1998 y 2014.

- Ha permitido atraer importantes inversiones, como el de Viettel en telecomunicaciones y el Industrial and Commercial Bank of China (ICBC).

- Abre perspectivas para la inyección de capitales como las del Consorcio Chino Minerals and Metal Group (62,5\%)-Guoxin International Investment (22.5\%) y CITIC Metal, con el 15\% de participación, que adquirió el proyecto Las Bambas por US\$ 7000 millones.

- El Foro le ha facilitado la firma de Acuerdos de Libre Comercio que han dinamizado los flujos de comercio e inversiones.

- Ha facilitado la movilidad de las personas. Ciudadanos peruanos pueden ingresar sin visa a diez países de APEC y hacer uso el Business Travel Card (ABTC) para sus negocios.

\footnotetext{
16 Global Investors Güide: Perú 2015-Milestone UK. (pp. 45, 46, 47). Recuperado de http://www.milestonegrp. co.uk/epub/peru2015/
} 
- 12 universidades conforman la Red Peruana para Estudios del Asia-Pacífico, REDAP, como parte del APEC Study Center Consortium enlazada, a su vez, con instituciones como UC Berkeley y el Taiwán Institute of Economic Research.

- Los empresarios peruanos, a través de ABAC Perú, han liderado el grupo de trabajo Pyme y Emprendimiento entre 2012-2014 como también en los grupos de Integración Económica Regional y Conectividad.

- El intercambio de buenas y mejores prácticas ha permitido lograr una mayor seguridad al interior de nuestras economías, incluida la del Perú.

Por el lado del Ministerio de Comercio Exterior y Turismo (Mincetur) se pueden resaltar los siguientes $\operatorname{logros}^{17}$ :

- El incremento de las inversiones asiáticas en el Perú.

- El crecimiento del turismo proveniente de las Economías APEC.

- La apertura del mercado, liberalización de la economía y fortalecimiento de la capacidad de gestión pública.

- El comercio y la reducción de los costos de transacción, en especial la mejora en procedimientos aduaneros; rápidos y eficientes.

- El flujo de intercambio corporativo y cultural con mayor dinamismo entre los miembros.

- Se estructuró una agenda para fortalecer las relaciones políticas, comerciales, económicas, financieras y turísticas con socios estratégicos del Asia-Pacífico

- Se avanzó en la conversión del Perú en un hub, por vía de acuerdos bilaterales con miembros APEC y actividades sobre infraestructura como de conectividad.

\section{Free Trade Area of the Asia-Pacific (FTAAP) - Área de Libre Comercio del Asia-Pacífico}

El FTAAP fue inicialmente propuesto por el Consejo Consultivo Empresarial de APEC, ABAC, y fue formalmente incluido en la Declaración de los Líderes de las Economías de 2004. En 2014, los Líderes de APEC aprobaron la Hoja de Ruta de Beijing ${ }^{18}$ para trabajar de una manera integral y sistemática la materialización del FTAAP.

\footnotetext{
17 Chan Sánchez, Julio (agosto de 2015). La Alianza del Pacifico y APEC. Agenda del Perú para el 2016. Presentación efectuada en Medellín, Colombia 2015. Recuperado de: http://www.kas.de/wf/doc/kas_16739-1442-1-30.pdf?15 0902212519

18 Declaración de Líderes APEC, Anexo A: Hoja de Ruta de la Contribución de APEC para la Realización del FTAAP. China 2014. Recuperado de http://www.acuerdoscomerciales.gob.pe/images/stories/apec/declaracion-china -2014/anexo_A_hoja_de_ruta_contribucion_apec_realizacion_ftaap_.pdf
} 
En la Hoja de Ruta de Beijing, anexo A de la Declaración de 2014, los Líderes encargaron a los funcionarios un Estudio Estratégico Colectivo sobre las Cuestiones Relacionadas con la realización del FTAAP. Al respecto, se ha logrado importantes progresos con esfuerzos conjuntos de todos los miembros y las partes interesadas, poniendo de relieve la voluntad y disposición de APEC para acelerar su concreción.

Los ministros de Comercio, reunidos en Boracay-Filipinas, aprobaron los Términos de Referencia (TOR) para realizar el Estudio Estratégico Colectivo. Estos establecen los objetivos, las responsabilidades, la estructura de la investigación, el alcance del trabajo, los entregables, los cronogramas, y los contenidos de los capítulos del estudio. También establece que se basará en trabajos anteriores, algunos de los cuales actualizará para proporcionar un análisis de los posibles beneficios y costos, económicos y sociales, de la FTAAP. Se identificarán las barreras comerciales y de inversión, así como los retos que las Economías tendrían que enfrentar en la realización del FTAAP. El estudio incluirá un balance de la Acuerdos Regionales así como los bilaterales, y un análisis de las distintas vías para llegar a su materialización y operatividad, incluyendo una evaluación de los impactos del fenómeno «spaghetti bowl» ${ }^{19}$ resultado de la firma de gran número de acuerdos comerciales.

La versión final del Estudio y su Resumen Ejecutivo, junto con las recomendaciones, será presentada a los Líderes en el Perú en noviembre del presente año (2016).

\section{APEC Perú 2016: «Crecimiento de Calidad y Desarrollo Humano»}

El Perú en 2016 preside y es anfitrión, por segunda vez, del Foro APEC. Ninguna otra Economía ha presidido el Foro en un período tan corto. La Cumbre de Líderes tendrá lugar los días 19 y 20 de noviembre próximo.

Como anfitriones de APEC 2016, Perú ha elegido como tema general: «Crecimiento de calidad y desarrollo humano ${ }^{20}$, proponiendo una estrategia orientada a facilitar el crecimiento equitativo y de calidad en la región, y la mejora de las estrategias de crecimiento que colocan al progreso social e individual como un punto central en este esfuerzo. Esta propuesta, implementada en el marco de las políticas del libre mercado y de apertura frente al comercio, brindará sostenibilidad y legitimidad a los procesos de desarrollo. La propuesta también se relaciona a la provisión del «Crecimiento Inclusivo» que fue lanzada por el gobierno peruano.

\footnotetext{
19 Cámara Chilena Norteamericana de Comercio. El Efecto Spaghetti Bowl del Libre Comercio (diciembre de 2004). Recuperado de http://www.amchamchile.cl/2004/12/el-efecto-spaghetti-bowl-del-libre-comercio/

20 APEC Perú 2016. Crecimiento de Calidad y Desarrollo Humano. Recuperado de http://www.apec2016.pe/es/ peru-host-2016/
} 
El concepto del desarrollo humano se utiliza en su sentido amplio, lo que implica los niveles de realización y satisfacción personal en diversas dimensiones, más allá del progreso que se mide de manera cuantitativa. Se construye sobre el espíritu de la presidencia anterior de APEC 2008, donde el Perú impulsó el concepto de «La Dimensión Social de la Globalización».

Las prioridades establecidas por el Perú para el APEC 2016 son las siguientes:

1. Integración Económica Regional y Crecimiento con Calidad (Regional Economic Integration and Quality Growth)

2. Modernización de las PyMEs (SMEs' Modernization)

3. Mercados de Alimentos (Food Markets)

4. Desarrollo de Capital Humano (Human Capital Development)

Las prioridades para la Agenda de Comercio e Inversiones son:

a) Integración Económica Regional, cuyos principales tópicos son:

Estudio sobre el Área de Libre Comercio del Asia-Pacifico (FTAAP): Se espera que los borradores del Estudio y de las Recomendaciones sean revisados por los ministros en la Reunión de Ministros Responsables de Comercio en mayo. Asimismo, se prevé que el Estudio y las Recomendaciones sean finalizados para la Cumbre de Líderes que se realizará en noviembre. El Perú está impulsando que la Declaración de Líderes incluya un párrafo con instrucciones para iniciar conversaciones hacia la realización del FTAAP fuera del APEC.

Metas de Bogor: El Perú es el encargado de coordinar la elaboración del reporte sobre el avance de las economías de APEC hacia la liberalización y facilitación del comercio. El primer borrador se presentará en la Reunión Ministerial de Comercio Exterior en mayo.

Fortalecimiento de capacidades para negociadores: Se realizarán talleres sobre negociaciones en Servicios e Inversiones.

Diálogo de Politicas sobre Acuerdos Comerciales: El objetivo es identificar las mejores prácticas sobre el aprovechamiento de los acuerdos comerciales y comparar las similitudes y diferencias de los TLC en la región.

Apoyo al Sistema Multilateral de Comercio: Se propondrá que los ministros de Comercio declaren la necesidad de mantener en la agenda de la Organización Mundial del Comercio las negociaciones para la eliminación de los subsidios a la pesca. 
b) Promover la internacionalización de las pymes y su inserción en las cadenas globales de valor, lo que contempla:

Iniciativa sobre inserción de las pymes en las cadenas globales de valor en industrias de servicios: El objetivo es facilitar el entendimiento entre hacedores de política, academia y sector privado de las cadenas de valor de algunas industrias de servicios, tales como: desarrollo de software, turismo, diseño de moda, producción y distribución de películas y call centers.

Taller sobre Comercio Electrónico como herramienta para la inclusión y competitividad de las pymes.

c) Mejorar la eficiencia en la cadena de suministros conectividad en la región, a través de:

Iniciativa sobre Ventanillas Únicas de Comercio Exterior (VUCE): El objetivo es construir un entendimiento común sobre ventanillas únicas para la región para promover la interoperabilidad de VUCE e intercambio de experiencias. Encuesta y taller sobre mejores prácticas en la implementación del Acuerdo de Facilitación del Comercio de la OMC

El Perú, en su calidad de país anfitrión realizará, entre diciembre de 2015 y noviembre de 2016, más de 160 reuniones, en sus 7 sedes (Arequipa, Iquitos, Lima, Piura, Tacna, Tarapoto y Trujillo):

- Cuatro reuniones ministeriales anuales (Comercio, Finanzas, Pymes, RREE-Comercio).

- Cuatro reuniones ministeriales sectoriales (Turismo, Foro de la Mujer y la Economía, Educación y Seguridad Alimentaria).

- Todos los 60 grupos de trabajo y subforos.

- Cuatro reuniones de Altos Funcionarios en 2016, cada una con 4 a 69 reuniones de subforos (hasta 150 sesiones).

- Una Reunión Informativa de Altos Funcionarios y un Simposio APEC a realizarse en diciembre de 2015.

- Cumbre Empresarial (aprox. 1500 CEO).

- Prensa Internacional (aprox. 3500 periodistas).

- Tres o más Diálogos de Alto Nivel entre socios público-privados.

- Reunión de Líderes de las 21 Economías en noviembre 2016. 
APEC PERU 2016, permitirá al país tener mucha exposición mediática y muchos visitantes, con los consiguientes efectos positivos para nuestra economía. Pero la oportunidad para que el Perú marque un hito histórico en APEC es que, en la Cumbre de Líderes de noviembre, anuncie la culminación del Estudio Estratégico Colectivo, sobre la conformación del Área de Libre Comercio del Asia-Pacífico (FTAAP) y se abra una nueva, como trascedente etapa en el proceso de formación de la Comunidad del Asia-Pacífico. El estudio afianzará una ambiciosa decisión de los Líderes en su Declaración de 2016 respecto del liderazgo que se viene demostrando en el proceso de integración más ambicioso del orbe.

\section{Bibliografía}

APEC. Policy Support Unit (November, 2010). Progressing towards the APEC Bogor Goals Perspectives of the APEC. Recuperado de http://publications.apec.org/publicationdetail.php?pub_id=1083.

APEC. Policy Support Unit (September, 2012). APEC's Bogor Goals Dashboard, August 2012. Recuperado de http://publications.apec.org/publication-detail.php?pub_id=1309.

APEC. Policy Support Unit (October, 2015). APEC's Bogor Goals Dashboard, October 2015. Recuperado de http://publications.apec.org/publication-detail.php?pub_id=1665.

APEC. Policy Support Unit (2015). APEC in Charts 2015 (pp. 3, 4, 5, 12, 23, 26). Recuperado de http://publications.apec.org/publication-detail.php?pub_id=1675

APEC Perú (2016). Crecimiento de calidad y desarrollo humano. Recuperado de http://www. apec2016.pe/es/peru-host-2016/

APEC. Secretariat (2016). Member Economies. Recuperado de http://www.apec.org/ About-Us/About-APEC/Member-Economies.aspx

APEC. Secretariat (2016). APEC Structure (February 2016). Recuperado de http://www. apec.org/About-Us/How-APEC-Operates/Structure.aspx

Cámara Chilena Norteamericana de Comercio (diciembre de 2004). El Efecto Spaghetti Bowl del Libre Comercio. Recuperado de http://www.amchamchile.cl/2004/12/ el-efecto-spaghetti-bowl-del-libre-comercio/

Chan Sánchez, Julio (2008). APEC y el Perú. Guía sobre el Foro de Cooperación Económica Asia-Pacifico y la participación del Perú. Recuperado de http://cendoc.esan.edu.pel fulltext/e-documents/apec/Apec\%20y\%20el\%20Peru.pdf

Chan Sánchez, Julio (agosto de 2015). La Alianza del Pacifico y APEC. Agenda del Perú para el 2016. Presentación efectuada en Medellín, Colombia. Recuperado de http://www. kas.de/wf/doc/kas_16739-1442-1-30.pdf?150902212519

Declaración de Líderes APEC (2014). Anexo A: Hoja de Ruta de la Contribución de APEC para la Realización del FTAAP. China 2014. Recuperado de http://www.acuerdoscomerciales.gob.pe/images/stories/apec/declaracion-china-2014/anexo_A_hoja_de_ ruta_contribucion_apec_realizacion_ftaap_.pdf 
González Vigil, Fernando y César Gala (2008). Conociendo APEC y sus temas. Lima: Universidad del Pacífico.

Global Investors Guide: Perú (2015). Milestone UK (pp. 45, 46, 47). Recuperado de http:// www.milestonegrp.co.uk/epub/peru2015/

Ministerio de Comercio Exterior y Turismo (2016). Acuerdos comerciales. Recuperado de http://www.acuerdoscomerciales.gob.pe/index.php?option=com_content\&view=cate gory\&layout $=$ blog\&id $=156 \&$ Itemid $=174$

Ministerio de Comercio Exterior. Dirección General de Investigación y Estudios sobre Comercio Exterior (2015). Reporte de Comercio Bilateral Perú-Foro de Cooperación Económica Asia-Pacífico (APEC). (Ene-Nov. 2015).

Obama, Barack (2015). Las reglas del comercio mundial las escribirá Estados Unidos. Recuperado de http://surhoy.org/2015/10/19/crisis-de-la-teoria-economica-y-corrupcion-tpp-yotros-acuerdos-comerciales/

Sociedad de Comercio Exterior del Perú, COMEX PERÚ (2016).¿Qué es ABAC? Recuperado de http://www.comexperu.org.pe/que_es_abac.aspx

Vásquez Vela, Edgar (2015). Seminario Académico sobre las Prioridades Nacionales Perú APEC 2016 organizado por la Red Peruana de Estudios del Asia Pacífico (REDAP). Lima, Perú (diciembre de 2015).

Fecha de recepción: 7 de marzo de 2016 Fecha de aprobación: 27 de abril de 2016 